\title{
Extrato hidroalcoólico de eucalipto, Eucalyptus dunnii, no controle do carrapato bovino, Rhipicephalus (Boophilus) microplus
}

\author{
Hydroalcoholic extract of eucalyptus Eucalyptus dunnii in the \\ control of the cattle tick Rhipicephalus (Boophilus) microplus
}

Maiara Kharoline Freitas de Oliveira ${ }^{[a]}$, Daniela Pedrassani[b]

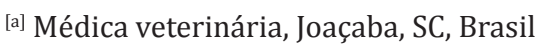

[b] Universidade do Contestado (UnC), Canoinhas, SC, Brasil

*Autor correspondente

E-mail: daniela@unc.br

\section{Resumo}

Rhipicephalus (Boophilus) microplus, artrópode hematófago e vetor de doenças importantes dos bovinos, tem causado grandes prejuízos econômicos para os produtores. Atualmente, os produtos utilizados para o seu controle vêm apresentando eficácia reduzida, devido ao seu uso indiscriminado e manejo inadequado. Em vista dessa resistência aos acaricidas, verifica-se a necessidade de encontrar novas alternativas de controle, como a fitoterapia. Este trabalho teve o objetivo de avaliar a eficiência in vitro do extrato hidroalcoólico de Eucalyptus dunnii, espécie comum na região subtropical do Brasil, sobre teleóginas de R. (B.) microplus, seguindo a metodologia do biocarrapaticidograma, para testar o extrato e o comparar com Amitraz 12,5\%. Os dados foram avaliados por análise de variância seguida de Teste de Tukey e análise de regressão linear. Foram testadas três concentrações do extrato (25, 50 e 75\%), que apresentaram eficácias de 49,5, 67,9 e 73,6\%, respectivamente. Na análise de regressão linear foi constatada associação significativa entre as concentrações do extrato testado e o peso dos ovos, eclodibilidade larval e a eficácia dos tratamentos. Foi verificada correlação negativa entre a concentração do extrato de E. dunni e o peso dos ovos e a eclodibilidade, enquanto para a eficácia a correlação foi positiva. Conclui-se que o extrato hidroalcoólico de E. dunnii, nas concentrações utilizadas, apresentou baixa e média eficácia contra teleóginas do carrapato bovino, apresentando maior interferência na eclodibilidade das larvas do que na postura das teleóginas, não podendo ser utilizado isoladamente no controle desse ectoparasito.

Palavras-chave: Carrapato bovino. Carrapaticida. Fitoterapia. Eucalipto. 


\section{Abstract}

The cattle tick Rhipicephalus (Boophilus) microplus, hematophagous arthropod vector of diseases of cattle, has been causing great economic losses to producers. Currently, products used for their control have reduced effectiveness due to their indiscriminate use and improper management. In view of this resistance to acaricides, there is the need to search for new alternatives of control, such as the phytotherapy. This study aimed to evaluate in vitro the efficacy of the hydroalcoholic extract of Eucalyptus dunnii, a common species in the subtropical region of Brazil, against engorged females of R. (B.) microplus, following the methodology of acaricide bioassay to test the extract and compare with Amitraz 12.5\%. The obtained data were appraised using analysis of variance followed by Tukey test and linear regression analysis. Three concentrations of the extract (25, 50 and 75\%) were tested, and they presented efficacies of 49.5, 67.9 and $73.6 \%$ respectively. On linear regression analysis, significant association was observed between concentrations of the extract and egg masses weight, larval hatchability and the effectiveness of treatments. Negative correlation between the concentration of extract of $\mathrm{E}$. dunni, egg masses weight, and larval hatchability was noticed, while for the effectiveness the correlation was positive. It is concluded that the hydroalcoholic extract of E. dunnii, in the concentrations used, presented low and medium effectiveness against engorged females of the cattle tick $\mathrm{R}$. (B.) microplus, showing greater interference on larval hatchability than in the engorged females oviposition. Moreover, it may not be used alone in the control of this ectoparasite.

Keywords: Cattle tick. Acaricide. Phytotherapy. Eucalyptus.

\section{Introdução}

O Brasil possui um dos maiores rebanhos bovinos do mundo (IBGE, 2015), e um ectoparasito que vem causando grandes prejuízos para os produtores é o Rhipicephalus (Boophilus) microplus, um artrópode hematófago vetor de doenças importantes e que atualmente vem resistindo aos produtos utilizados para o seu controle (Yoneya, 2009). O R. (B.) microplus ocasiona prejuízos pela diminuição da produção animal, pela desvalorização do couro, transmissão de importantes patógenos e gastos na tentativa de seu controle, levando a perdas de mais de 3,24 bilhões de dólares anuais no Brasil (Grisi et al., 2014). A fim de evitar tais prejuízos, os produtores utilizam há anos diversos produtos carrapaticidas, porém como não há no Brasil qualquer política oficial de controle do carrapato comum dos bovinos, práticas de controle individuais têm sido adotadas (Carvalho; Costa, 2007).

A carência de informações, na maioria das vezes, é a maior causa do uso incorreto e indiscriminado desses produtos pelos produtores, uma das causas para a resistência adquirida pelo $R$. (B.) microplus, atuando conjuntamente com os fatores genéticos (seleção) próprios do carrapato. Essa situação deve ser encarada como sério problema para a pecuária, em virtude da dificuldade no controle dessa praga após sua instalação (Saueressig, 1999; Martins, 2006).

Verifica-se a necessidade de se encontrar nova alternativa de controle à qual o $R$. (B.) microplus ainda não apresente mecanismo de resistência, e que de preferência gere menores riscos à saúde humana e ambiental e minimize as perdas dos produtores.

0 extrato de Eucalyptus spp. possui ação repelente e inseticida (Chagas, 2002; Clemente, 2007), o que pressupõe que soluções constituídas por esse extrato apresentem mesmo modo de ação no controle de demais artrópodes, como o carrapato bovino. Atualmente está sendo analisada sua ação no controle dessa espécie por ser uma alternativa que abrange todos os pontos positivos que se espera de um novo produto, além de ser sustentável e ambientalmente correto.

A utilização do extrato de eucalipto contra carrapatos possui inúmeras vantagens, mas dentre 
as mais importantes estão a não resistência desses parasitos ao princípio ativo do eucalipto, o que pode conduzir a uma grande eficácia do produto e à abrupta diminuição no tempo de permanência de resíduos no leite e na carne.

Eucalyptus dunnii, espécie largamente cultivada na região Sul do Brasil por sua resistência a geadas, possui grande importância econômica, pois é uma espécie que fornece madeira para a intensa produção de energia renovável na região, entre outros produtos, e dentre essas utilidades nenhuma aproveita suas folhas que acabam sendo descartadas.

Com base nos estudos até então realizados, a ação do óleo de Eucalipto, a partir de suas folhas, no controle de $R$. (B.) microplus, apresentou resultados que variaram de acordo com os níveis de sua concentração utilizada, mas o seu custo é relativamente alto, justificando a necessidade de estudos complementares.

Assim sendo, este trabalho teve como objetivo avaliar o efeito in vitro do extrato hidroalcoólico de $E$. dunnii sobre teleóginas do carrapato do boi, $R$. (B.) microplus.

\section{Material e métodos}

A espécie utilizada para a preparação do extrato foi E. dunnii, por ser uma das espécies mais cultivadas na região sul do Brasil, tendo em vista a utilização de sua madeira. A coleta foi realizada na Universidade do Contestado - UnC, Campus de Canoinhas, e após identificação uma exsicata está mantida no Herbário do Curso de Engenharia Florestal da UnC. Após a coleta, as folhas foram laceradas e permaneceram imersas por 15 dias em Becker coberto por papel alumínio, numa solução de etanol PA: água (7:3 v/v). Após 15 dias, a mistura foi filtrada com papel filtro, separando o conteúdo sólido (folhas laceradas) do líquido, para colocação em banho-maria a $45^{\circ} \mathrm{C}$, onde permaneceu até obtenção do extrato bruto. 0 extrato hidroalcoólico obtido foi diluído em água até as concentrações de $25 \%, 50 \%$ e $75 \%$ para a realização dos bioensaios in vitro.

A coleta das teleóginas de $R$. (B.) microplus foi realizada em uma propriedade de criação de bovinos de leite localizada no município de Canoinhas /SC, onde foram coletadas 200 teleóginas com comprimento superior a $4,5 \mathrm{~mm}$, presentes em bovinos da raça Holandesa naturalmente infestados, isentos de tratamento com carrapaticida químico de contato por pelo menos 21 dias. Foram selecionadas 150 teleóginas (sem má formação, com boa motilidade, sem lesões, sem resquícios de tegumento no aparelho bucal), que foram lavadas em água destilada, secas em papel absorvente, distribuídas em grupos de cinco e pesadas.

0 delineamento experimental foi inteiramente casualizado com seis tratamentos e cinco repetições, considerando-se cinco teleóginas como repetição.

0 primeiro grupo foi representado por teleóginas tratadas com água (controle negativo/ nível zero), sendo a mesma água usada para a diluição dos extratos e do carrapaticida. 0 segundo, com teleóginas tratadas com água e álcool P.A. (na proporção 3:7, mesma usada para a maceração do extrato). E o terceiro, com um carrapaticida de contato já testado e com eficácia de 100\% em carrapatos dessa propriedade (Pedrassani; Reisdorfer, 2015), o Amitraz 12,5\% (amidina/ concentração de 0,025\% após diluído). Os demais tratamentos foram com as diluições do extrato hidroalcoólico de E. dunnii em 25\%, 50\% e 75\%. Após preparo de $500 \mathrm{~mL}$ de cada tratamento, as teleóginas ficaram imersas por cinco minutos no tratamento respectivo.

Em seguida, as fêmeas foram secas em papel absorvente, fixadas em placas de Petri e mantidas em estufa BOD a $27^{\circ} \mathrm{C}( \pm 1)$ e $80 \%( \pm 5)$ de umidade relativa, sendo avaliadas diariamente até o décimo oitavo dia.

Aos 18 dias do início do experimento, as massas de ovos foram retiradas, pesadas e transferidas para tubos de ensaio vedados com gaze e identificados. Após o período de incubação de sete dias foi estimado o percentual de eclosão de larvas de cada grupo.

Foram registrados mortalidade das teleóginas (reação positiva ou negativa ao toque com pinça), tempo de letalidade (período transcorrido entre a imersão no tratamento e a morte das fêmeas), número de oviposições, peso das massas de ovos, percentual de eclodibilidade por meio de uma escala que variou de 0 (ausência de eclosões) a 4 (100\% de larvas eclodidas), e eficácia do produto. 


\section{Análise estatística}

Os dados registrados e avaliados foram: peso médio dos ovos (g), peso das teleóginas (g), porcentagem de fêmeas mortas (porcentagem de mortas, \%), porcentagem de eclosão após 15 dias (porcentagem de eclosão, \%), porcentagem de teleóginas que apresentaram postura (\%), eficácia reprodutiva (ER, \%) e eficácia de tratamento (ET, \%). 0 cálculo da ER e da ET foi realizado de acordo com metodologia sugerida por Drummond et al. (1973): $\mathrm{ER}=$ ((peso ovos (g)/peso teleóginas (g)) x \% eclosão $\times$ 20.000) e ET = ( (ER grupo controle - ER grupo tratado)/ ER grupo controle) x 100 .

As variáveis analisadas foram peso (g) das teleóginas de R. (B.) microplus anterior à imersão nos tratamentos, peso dos ovos (g), eclodibilidade (\%) e eficácia (\%). Os dados dos grupos independentes foram avaliados por análise de variância seguida de Teste de Tukey, para a comparação de médias, com $\alpha$ de $5 \%(\mathrm{P} \leq 0,05)$.

Os dados de peso dos ovos (g), eclodibilidade (\%) e eficácia (\%) dos tratamentos dependentes $\left(\mathrm{H}_{2} \mathrm{O}\right.$, extrato $25 \%$, extrato $50 \%$ e extrato $75 \%$ ) obtidos foram submetidos à análise estatística de regressão linear. As análises foram realizadas no programa IBM SPSS ${ }^{\circledR}$ statistics versão 21.

\section{Resultados e discussão}

No primeiro dia após a imersão das teleóginas, $12 \%$ das tratadas com o extrato $75 \%$ haviam morrido, e essa mortalidade aumentou rapidamente até o $18^{\circ}$ dia de observação, chegando a $100 \%$ juntamente com as tratadas com extrato $50 \%$; as fêmeas do tratamento a $25 \%$ chegaram a $88 \%$ de mortalidade, valores muito acima da letalidade dos demais grupos (Figura 1). Parte da mortalidade do extrato a 75\% talvez seja devido à elevada viscosidade da solução, podendo ter recoberto o peritrema das teleóginas dificultando sua respiração.

Os dados obtidos para o parâmetro peso das teleóginas (g), anterior à realização da imersão nos tratamentos, mostram não haver diferença significativa entre os grupos utilizados, o que indica que quanto a esse fator os grupos foram similares, não interferindo nos resultados da pesquisa (Tabela 1).

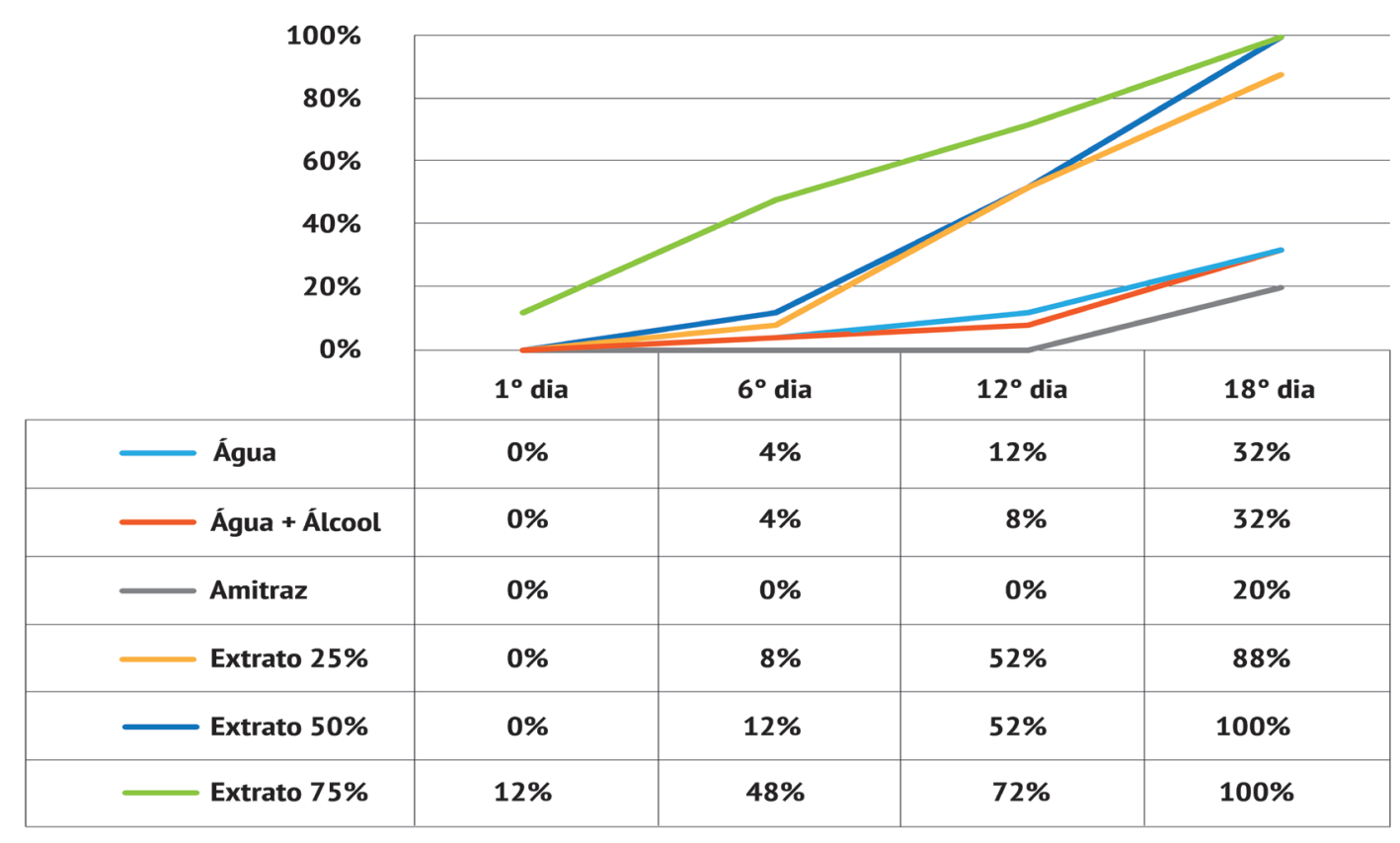

Figura 1 - Mortalidade (\%) nos dias $1^{\circ}, 6^{\circ}, 12^{\circ}$ e $18^{\circ}$, das teleóginas de Rhipicephalus (Boophilus) microplus submetidas aos tratamentos carrapaticidas testados. 
Tabela 1 - Média ( \pm desvio) padrão do peso das teleóginas ( $g$ ) de Rhipicephalus (Boophilus) microplus, peso dos ovos ( $g$ ), eclodibilidade (\%) e eficácia (\%) dos tratamentos com os extratos hidroalcoólicos de Eucalyptus dunnii, Amitraz e controles aquoso e hidroalcóolico

\begin{tabular}{ccccc}
\hline & Peso Teleóginas $(\mathrm{g})$ & Peso ovos $(\mathrm{g})$ & Eclodibilidade (\%) & Eficácia (\%) \\
\hline H20 & $0,882 \pm 0,06^{\mathrm{a}}$ & $0,409 \pm 0,10^{\mathrm{a}}$ & $98,00 \pm 1,14^{\mathrm{a}}$ & $0,00 \pm 0,00^{\mathrm{a}}$ \\
H20 +álcool & $0,881 \pm 0,04^{\mathrm{a}}$ & $0,377 \pm 0,06^{\mathrm{a}}$ & $96,20 \pm 1,30^{\mathrm{a}}$ & $10,08 \pm 14,43^{\mathrm{a}}$ \\
Amitraz & $0,879 \pm 0,06^{\mathrm{a}}$ & $0,020 \pm 0,02^{\mathrm{c}}$ & $0,020 \pm 0,04^{\mathrm{b}}$ & $100,00 \pm 0,00^{\mathrm{b}}$ \\
Extrato 25\% & $0,875 \pm 0,06^{\mathrm{a}}$ & $0,272 \pm 0,04^{\mathrm{ab}}$ & $74,00 \pm 15,57^{\mathrm{a}}$ & $49,56 \pm 12,53^{\mathrm{c}}$ \\
Extrato 50\% & $0,879 \pm 0,05 \mathrm{a}$ & $0,264 \pm 0,08^{\mathrm{ab}}$ & $47,80 \pm 10,32^{\mathrm{c}}$ & $67,94 \pm 15,20^{\text {cd }}$ \\
Extrato75\% & $0,883 \pm 0,05^{\mathrm{a}}$ & $0,212 \pm 0,12^{\mathrm{b}}$ & $42,60 \pm 25,07^{\mathrm{c}}$ & $73,62 \pm 17,27^{\mathrm{d}}$ \\
\hline
\end{tabular}

Nota: Letras diferentes na coluna indicam diferença estatisticamente significativa pelo teste de Tukey $(P \leqslant 0,05)$.

As teleóginas imersas em água destilada e água destilada + álcool, realizaram $84 \%$ e $96 \%$ de postura respectivamente, com ovos totalmente viáveis, já dentre as imersas em amitraz, somente $24 \%$ realizou postura, sendo essa com $100 \%$ dos ovos inviáveis.

Das fêmeas ingurgitadas tratadas com o extrato $25 \%, 92 \%$ realizaram postura, sendo que $12 \%$ foram posturas parciais. Das tratadas com o extrato $50 \%, 84 \%$ apresentaram postura positiva, e as do tratamento com extrato $75 \%$ apresentaram postura de $68 \%$, sendo que a postura de ambos os tratamentos apresentou 8\% de teleóginas com posturas parciais (Figura 2).

Avaliando a postura das teleóginas, os dados evidenciaram não haver diferença significativa no peso dos ovos (g) dos grupos tratados com o extrato quando comparados aos tratamentos com $\mathrm{H}_{2} \mathrm{O} \mathrm{e}_{2} \mathrm{O}$ + álcool, diferindo somente do grupo tratado com Amitraz, que inibiu a postura de $76 \%$ das teleóginas (Figura 2); ou seja, o extrato em suas diferentes concentrações não interferiu significativamente na oviposição (Tabela 1).

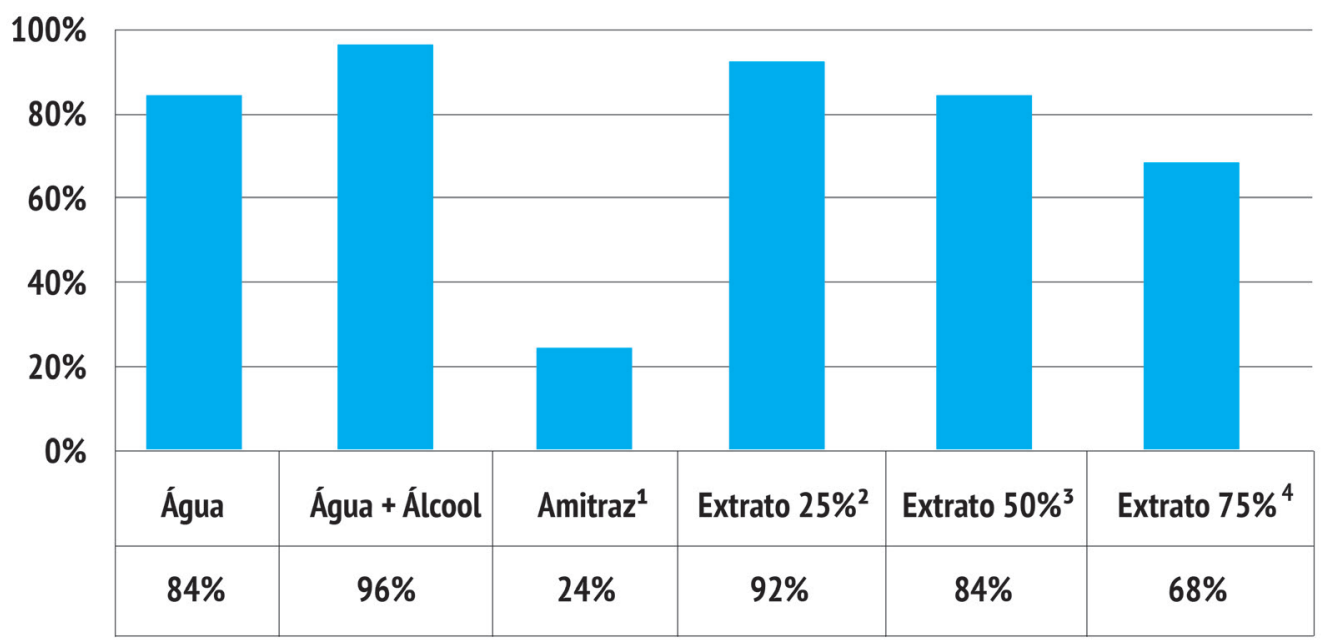

Nota: ${ }^{1} 24 \%$ das teleóginas realizaram posturas inviáveis; ${ }^{2} 12 \%$ realizaram posturas parciais; ${ }^{3} 8 \%$ realizaram posturas parciais; ${ }^{4} 8 \%$ realizaram posturas parciais.

Figura 2 - Teleóginas de Rhipicephalus (Boophilus) microplus que apresentaram postura positiva (\%). 
$\mathrm{Na}$ análise de regressão linear com os dados de pesos de ovos $(\mathrm{x})$ e concentração de extrato hidroalcoólico de E. dunnii (y) foi verificada associação significativa $(\mathrm{P}<0,05)$ expressa pela equação $\mathrm{y}=0,380-0,060 \mathrm{x}$. Foi observado que quanto ao peso dos ovos (g), com coeficiente de regressão (R) 0,606 e significância de 0,005, a cada nível que o extrato aumentou poderia diminuir $0,060 \mathrm{~g}$ de peso dos ovos.

Analisando o aspecto dos ovos, as fêmeas que realizaram postura produziram ovos brilhantes e de coloração amarronzada, indicativo de fertilidade, mas as teleóginas tratadas com Amitraz, 24\% das que realizaram postura produziram ovos mais escuros e secos; as demais expeliram uma secreção amarelada, possivelmente devido ao seu potencial ovariostático e antiembriogênico, citado por Merlini e Yamamura (1998).

Os resultados para o parâmetro eclodibilidade evidenciaram que houve influência do extrato na taxa de eclosão das larvas quando comparados aos tratamentos com $\mathrm{H}_{2} \mathrm{O}, \mathrm{H}_{2} \mathrm{O}+$ álcool e Amitraz nas concentrações de $50 \%$ e $75 \%$, que proporcionaram $47,8 \%$ e $42,6 \%$ de eclodibilidade, respectivamente, resultando em larvas eclodidas, juntamente com ovos intactos. Os valores são muito superiores ao do tratamento com Amitraz, com 0,02\% de eclodibilidade, o que resultou em ovos inviáveis, sem conteúdo em seu interior. Já na concentração de $25 \%$, o extrato não diferiu estatisticamente dos grupos tratados com $\mathrm{H}_{2} \mathrm{O}$ e $\mathrm{H}_{2} \mathrm{O}+$ álcool (Tabela 1).

$\mathrm{Na}$ análise de regressão linear com os dados de eclodibilidade $(x)$ e concentração do extrato $(y)$, verificou-se associação significativa $(P<0,05)$ expressa na equação y $=94,460-19,240 \mathrm{x}$. Em relação à eclodibilidade (\%), com coeficiente de regressão 0,820 e significância de 0,000, a cada nível que o extrato aumentou, poderia diminuir $19,2 \%$ de larvas eclodidas.

Quanto à eficácia, os tratamentos com o extrato hidroalcoólico de E. dunnii diferiram estatisticamente quando comparados aos grupos $\mathrm{H}_{2} \mathrm{O}, \mathrm{H}_{2} \mathrm{O}+$ álcool e Amitraz (Tabela 1). A eficácia foi crescente à medida que as concentrações dos extratos foram aumentadas: 49,5\% de eficácia com o extrato a $25 \%, 67,9 \%$ com o extrato a $50 \%$ e $73,6 \%$ com o extrato a $75 \%$.

$\mathrm{Na}$ análise de regressão linear com os dados de eficácia do tratamento $(\mathrm{x})$ e concentração do extrato (y), verificou-se associação significativa (P $<0,05)$ expressa na equação $y=11,903+23,925 x$. Quanto à eficácia, com coeficiente de regressão 0,856 e significância de 0,000 , a cada nível que a concentração do extrato aumentou, a eficácia poderia aumentar $23,9 \%$.

Foi verificada correlação negativa entre concentração do extrato de E. dunni, peso dos ovos (g) (Correlação de Pearson - 0,606) e eclodibilidade (\%) (Correlação de Pearson - 0,820). Para a eficácia (\%), a correlação foi positiva (Correlação de Pearson $0,856)$.

Para um produto químico comercial ser considerado de alta eficácia, ele precisa eliminar mais de $95 \%$ dos carrapatos, de média eficácia entre $90-95 \%$ e de baixa eficácia menos de 90\% (Brasil, 1997). No presente estudo, seguindo essa classificação, o extrato hidroalcoólico de $E$. dunnii apresentou baixa eficácia, pois mesmo em sua maior concentração alcançou apenas $73,6 \%$ de eficácia, não podendo ser utilizado isoladamente como alternativa de tratamento carrapaticida.

Outros estudos com o óleo essencial de distintas espécies de eucalipto chegaram a 100\% de eficácia (Chagas et al., 2002; Agnolin, 2012; Olivo et al., 2013), mas devido ao alto custo desse óleo, procurou-se elaborar um produto de forma mais simples e economicamente viável ao produtor, como um extrato hidroalcoólico, sabendo que cada espécie da planta possui quantidade variável do composto responsável pela ação acaricida, 1,8-cineol ou eucaliptol. Sefstrom (2011) cita que a concentração desse metabólito no óleo essencial de E. dunnii é de 60,74\%. Costa et al. (2008) avaliaram a eficácia in vitro do extrato hidroalcoólico de Eucalipto (Eucalyptus sp.) a 10\% sobre fêmeas ingurgitadas de $R$. (B.) microplus e obtiveram uma eficácia de $96 \%$.

Apesar do extrato de E. dunnii ter apresentado algum efeito sobre as teleóginas de $R$. (B.) microplus, postura e eclodibilidade de larvas, dificilmente seria utilizado um extrato que esteja em tão altas concentrações. Pode-se perceber, também, que mesmo aumentando a concentração do extrato, a eficácia apresentou pouca alteração.

Chagas et al. (2002) esclareceram que para um bioativo ter efeito e ser absorvido pelos artrópodes, 
ele precisa ser hidrofílico e lipolítico, e quando um produto está altamente concentrado ocorre um fenômeno físico denominado apassivação. Nesse fenômeno, o produto é inicialmente absorvido, mas em seguida forma um filme apassivador que barra a passagem do óleo, o que não ocorre quando o produto está mais diluído, pois as moléculas dos monoterpenos se ligam facilmente à água, formando partículas menores. Assim, o filme não se forma e a penetração ocorre mais lentamente, porém de maneira mais devastadora.

Segundo Chungsamarnyart et al. (1991), a utilização das plantas como alternativa de terapia carrapaticida está cada vez mais ganhando espaço, pois além de ser menos agressiva ao meio ambiente, tende a apresentar níveis baixos de toxidez aos mamíferos e possui baixa degradação e um lento desenvolvimento à resistência.

Vale ressaltar que trata-se de um extrato bruto, que pode ser aperfeiçoado utilizando-se maiores frações de seu metabólito mais ativo, o 1,8-cineol, ou até mesmo utilizando-se solventes mais polares para sua elaboração, como o acetato de etila, visto na cromatografia realizada que, por sua maior polaridade, carregou em maior escala os metabólitos do extrato na placa cromatográfica quando em maior concentração. Todavia, apesar de sua alta polaridade, torna-se difícil formular um produto com essa substância devido a sua alta toxicidade.

\section{Conclusão}

O extrato hidroalcoólico de E. dunnii, produzido para esse estudo, nas concentrações utilizadas apresentou baixa e média eficácia contra teleóginas de $R$. (B.) microplus, apresentando maior interferência na eclodibilidade larval do que na postura das teleóginas.

Entretanto, novos estudos devem ser conduzidos com o foco na emulsificação do extrato de E. dunnii, obtendo menores concentrações e facilitando a absorção dos monoterpenos pelas teleóginas de $R$. (B.) microplus, fator esse que pode resultar em valores mais altos de eficácia; ou ainda, pelo isolamento de frações dos monoterpenos presentes na planta e/ou uso de solventes mais polares para elaboração do extrato.

\section{Referências}

Agnolin CA. Avaliação de óleos essências de capim-limão, citronela e eucalipto no controle do carrapato [tese]. Santa Maria: Universidade Federal de Santa Maria; 2012. 75 p.

Brasil. Ministério da Agricultura, Pecuária e Abastecimento. Secretaria de Defesa Agropecuária. Portaria no 48, de 12 de maio de 1997. Diário Oficial da União. 12 maio 1997; Seção 1. p. 10165-9.

Carvalho AV, Costa LM. Carrapato dos bovinos (Boophilus microplus) e resistência a carrapaticidas. 2007 [acesso 01 set. 2013]. Disponível em: https://tinyurl.com/ybn65tps.

Chagas ACS, Passos WM, Prates HT, Leite RC, Furlong J, Fortes ICP. Efeito acaricida de óleos essenciais e concentrados emulsionáveis de Eucalyptus spp em Boophilus microplus. Braz J Vet Res Anim Sci. 2002;39(5):247-53.

Chagas AJS. Controle de parasitas utilizando extratos vegetais. Rev Bras Parasitol Vet. 2004;13(Supl. 1):156-60.

Chungsamarnyart N, Rattanakrithakul C, Jiwajinda S. Practical extraction of sugar apple seeds against tropical cattle ticks. Kasetsart Journal (Nat Sci Suppl). 1991;25:101-5.

Clemente MA, Gomes FT, Scotton ACBS, Goldner MS, Reis ES, Almeida MC. Avaliação do potencial de plantas medicinais no controle de Boophilus microplus (Acari: Ixodidae). R Bras Bioci. 2007;5(Supl. 2):516-8.

Costa FB, Vasconcelos PSS, Silva AMM, Brandão VM, Silva IA, Teixeira WC, et al. Eficácia de fitoterápicos em fêmeas ingurgitadas de Boophilus microplus, provenientes da mesorregião oeste do Maranhão, Brasil. Rev Bras Parasitol Vet. 2008;17 (Supl. 1):83-6.

Grisi L, Leite RC, Martins JR, Barros AT, Andreotti R, Cançado PH, etal. Reassessment of the potential economic impact of cattle parasites in Brazil. Rev Bras Parasitol Vet. 2014;23(2):150-6.

IBGE. Instituto Brasileiro de Geografia e Estatística. Produção da Pecuária Municipal. 2015 [acesso 25 fev. 2017]. Disponível em: https://tinyurl.com/y8vk7u3s. 
Martins RM. Estudo in vitro da ação acaricida do óleo essencial da gramínea Citronela de Java (Cymbopogon winterianus Jowitt) no carrapato Boophilus microplus. Rev Bras Pl Med. 2006;8(2):71-8.

Merlini LS, Yamamura MH. Estudo in vitro da resistência de Boophilus microplus a carrapaticidas na pecuária leiteira no norte do estado do Paraná. Semina: Ci Agr. 1998;19(1):38-44.

Olivo CJ, Agnolin CA, Parra CLC, Vogel FSF, Richards NSPS, Pellegrini LG, et al. Efeito do óleo de eucalipto (Corymbia citriodora) no controle do carrapato bovino. Cienc Rural. 2013;43(2):331-7.

Pedrassani D, Reisdorfer S. Avaliação da eficácia in vitro de carrapaticidas comerciais. Arch Vet Sci. 2015;20(Supl.1):17-29.

Saueressig TM. Resistência do carrapato Boophilus microplus a carrapaticidas no Brasil Central. Planaltina: Embrapa Cerrados; 1999.

Sefstrom C. Extração e identificação do óleo essencial obtido de folhas e galhos das espécies Pinus taeda e Eucalyptus dunni cultivadas no Sudoeste do Paraná [trabalho de conclusão de curso]. Pato Branco: Universidade Tecnológica Federal do Paraná; 2011. 42 p.

Yoneya F. Carrapato bovino está cada vez mais resistente. 2009 [acesso 25 ago. 2013]. Disponível em: https:// tinyurl.com/y9oegxq6.

Recebido em: 08/03/2017

Received in: 03/08/2017

Aprovado em: 22/06/2017

Approved in: 06/22/2017 